Bergen, J.E.A.M. van, Kerssens, J.J., Schellevis, F.G., Sandfort, T.G., Coenen, T.T., Bindels, P.J. Sexually transmitted infection health-care seeking behaviour in the Netherlands: general practitioner attends to the majority of sexually transmitted infection consultations. International Journal of STD \& AIDS: 2007, 18(6), 374379

\begin{tabular}{|l|l|}
\hline Postprint Version & 1.0 \\
\hline Journal website & $\underline{\text { http://ijsa.rsmjournals.com/cgi/reprint/18/6/374 }}$ \\
\hline Pubmed link & $\underline{\text { http://www.ncbi.nlm.nih.gov/pubmed/17609024 }}$ \\
\hline DOI & $10.1258 / 095646207781024883$ \\
\hline
\end{tabular}

This is a NIVEL certified Post Print, more info at http://www.nivel.eu

\title{
Sexually transmitted infection health-care seeking behaviour in the Netherlands: general practitioner attends to the majority of sexually transmitted infection consultations
}

\author{
JAN EAM VAN BERGEN MD PHD ${ }^{*}$, JAN J KERSSENS MD PHD -, FRANCOIS G SCHELLEVIS MD PHD - \\ , THEO G SANDFORT PHD, TON T COENEN MPH* AND PATRICK J BindELs MD PHD ${ }^{\S}$
}

\begin{abstract}
*STI AIDS The Nederland (Soa Aids Nederland), Amsterdam; -NIVEL, Netherlands Institute for Health Services Research, Utrecht, The Netherlands; HIV Centre for Clinical and Behavioral Studies, New York State Psychiatric Institute and Columbia University, New York, NY, USA;

${ }^{\S}$ Department of General Practice, Academic Medical Centre-University of Amsterdam, The Netherlands
\end{abstract}

SUMMARY: Health-care seeking behaviour for sexually transmitted infection (STI)-related symptoms is not well known in the Netherlands. Within the framework of a large representative study, the second National Survey of General Practice (NIVEL 2001), 9687 persons aged 18 years and older were interviewed about their STI and STI-related health-care seeking behaviour.

In total, $1.2 \%$ of the interviewees reported STI-related symptoms in the past year (18-24 years: 5\%). A (lifetime) history of STI was reported by 2.7\% (18-44 years: 4\%). In all, 63\% of interviewees visited their general practitioner (GP) for these complaints; $20 \%$ went to an STIclinic and/or municipal public health services and $8 \%$ to a different care-provider. A total of $9 \%$ did not undertake any action. The majority of persons with STI-related symptoms in the Netherlands visit the GP.

Reported history of STI-related symptoms was twice lower in the Netherlands compared with the UK National Sexual Health Survey. Appropriate attention for sexual health in primary care is needed.

\section{INTRODUCTION}

In the Netherlands, in the four largest cities, there are six sexually transmitted infection (STI) clinics that render free and anonymous care. The Amsterdam STI clinic is the most frequently visited clinic with 18,500 new consultations in 2002. Since 1999, a steep increase in STI has been reported by the clinic, especially in high-risk groups like men who have sex with men (MSM) and in specific ethnic minorities such as the Surinamese-Antillean people. ${ }^{1}$ Outside the Amsterdam region, there are 37 other municipal public health services (MHS), some of which have treatment facilities for STI. ${ }^{2}$ In 2002, more than 23,500 new consultations were seen by these MHS and STI clinics outside Amsterdam. From 2000 to 2002, the number of consultations in these MHS rose by 50\% and the number of performed HIV tests by $75 \%$. In the same period, the total number of gonorrhoeal and chlamydial infections rose by $62 \%$, syphilis by $118 \%$ and HIV-infections by $130 \%{ }^{3}$ This resurgence of STI in the new millennium has also 
Bergen, J.E.A.M. van, Kerssens, J.J., Schellevis, F.G., Sandfort, T.G., Coenen, T.T., Bindels, P.J. Sexually transmitted infection health-care seeking behaviour in the Netherlands: general practitioner attends to the majority of sexually transmitted infection consultations. International Journal of STD \& AIDS: 2007, 18(6), 374379

been reported in other European countries. ${ }^{4}$ However, surveillance data from STI and MHS clinics do not necessarily reflect community patterns, as patients with STI-related problems can also visit other careproviders. ${ }^{5}$ In the Netherlands, the general practitioner (GP) is the core primary care-provider, and all inhabitants are registered in a general practice. It is assumed that the GP plays an important part in STI care, but few data are available. ${ }^{2}$ Information on how many people consult their GP for STIrelated problems is necessary to get insight into the role of primary care in STI care, to be able to estimate the population burden of STI disease and to guide health policy planners. ${ }^{6}$ In this article, we describe how often STIrelated problems are reported in a representative Dutch population sample and what is the current healthcare seeking behaviour for STI-related problems in the Netherlands.

Additionally, we studied whether risk factors for current and previous infection in the community differ from the ones identified in STI surveillance data based on STI clinics.

\section{METHODS}

\section{Dutch National Survey of General Practice}

This study took place within the framework of the second Dutch National Survey of General Practice (2NSGP) of NIVEL (National Institute for Research in Primary Care). It was carried out in 2001 in cooperation with the National Information Network of General Practice (NINGP). The first national survey was conducted in 1987. The aim of these large national surveys is to obtain information on health status, health-care utilization and quality of primary care. In this second national survey, data were collected about health and health-care related behaviour of 399,068 persons registered in 104 practices with 195 GPs. Population, practices and GPs were a representative sample of the Dutch society, with a slight underrepresentation of GPs who practised singly and were not in a group practice.

Study design and response have been published elsewhere in more detail. ${ }^{7}$ A broad range of health-related issues were collected as part of a computer-assisted structured health interview of 90 minutes at the home of randomly selected participants.

In total, 19,685 Dutch-speaking citizens were approached for interviewing. Interviewing was evenly distributed throughout one year to incorporate seasonal variation.

\section{Questions on STI-related problems}

The following four questions about STI and STI-related health-care seeking behaviour were collected during the home interview with the randomly selected participants: (1) 'In the past 12 months, did you have any signs or symptoms suggestive of a sexually transmitted infection (STI)'?; (2) If yes, 'what did you do'?; (3) if yes: 'was actually an STI diagnosed'?; (4) 'Did you ever have any STI before this last year'? Because a parent was present during the interview, if the person was below 18 year of age, sensitive issues like questions about sex were included only for persons aged 18 year or older.

For the present analysis, the answers on the four STIrelated questions were extracted from the central 2NSGP study database together with data on ethnicity, age, gender, marital status, education, net income, sexual behaviour and living in a rural/urban area or a deprived/not deprived area.

\section{Statistical analysis}

Ethnicity was defined according to the country of birth of the parents. If the mother was Dutch, nonDutch ethnicity was defined according to the country of birth of the father. If both parents were non-Dutch, the country of birth of the mother was taken as the definition. Persons were classified as Dutch, Surinamese-Antillean, Turkish/Moroccan or other.

Urban-rural classification of the practice was related to the Area Address Density (AAD) according to Statistics Netherlands: very high urban ( $>2500$ addresses $\left./ \mathrm{km}^{2}\right)$, semi-high-urban $\left(500-2500\right.$ addresses $/ \mathrm{km}^{2}$ ) and rural $\left(<500\right.$ addresses $\left./ \mathrm{km}^{2}\right)$.

Deprived areas were defined according to existing health insurance categories and related to neighbourhoods with low socioeconomic status and multiethnic population.

Univariate logistic regression analyses were performed, with the various characteristics (Table 1) as independent variables and STI-related symptoms or history of STI as the dependent variable. $P<0.05$ was considered statistically significant. In order to investigate the various patient characteristics simultaneously, multivariate logistic regression analyses were performed. Variables showing an association of $P<0.2$ were included in the multivariate analysis. Backward stepwise selection was performed with a $P$-value for the 
Bergen, J.E.A.M. van, Kerssens, J.J., Schellevis, F.G., Sandfort, T.G., Coenen, T.T., Bindels, P.J. Sexually transmitted infection health-care seeking behaviour in the Netherlands: general practitioner attends to the majority of sexually transmitted infection consultations. International Journal of STD \& AIDS: 2007, 18(6), 374379

likelihood ratio-test $>0.10$ as criteria for elimination of variables from the model. The goodness of fit (reliability) of the final model was tested by the Hosmer- Lemeshow statistic.

\section{RESULTS}

\section{Response and general characteristics}

Of the 19,685 persons approached for interviewing, 12,699 (64.5\%) were willing to be interviewed. The distribution of the respondents according to age, gender and place of residence are comparable with the original sample population.

Except for a slight under-representation of ethnic minorities, the participants are a representative sample of the Dutch population. In Table 1, the general characteristics of the respondents are presented. Of the interviewees, 9685 were aged 18 years or older; 5357 were women and 4328 men. A total of $65 \%$ were married, while $80 \%$ had Dutch nationality and $4 \%$ reported a homo-/bisexual orientation.

\section{STI-related symptoms in previous 12 months}

In total, 1.2\% (116/9685) reported STI-related signs or symptoms in the past year. The highest prevalence of STIrelated symptoms was reported in the Surinamese/ Antillean group (6.4\%) and in the age group 1824 years (4.8\%). Of all persons reporting STI-related symptoms, 58\% was between 18 and 34 years. Of all those with STI-related symptoms, 20\% lived in rural areas.

A significant association was found between reporting STI-related symptoms and young age, being single, homosexually orientated and being of non-Dutch origin (especially Surinamese/Antillean) (Table 1). Also, participants registered in highly urbanized practices and in practices in deprived areas reported more STI-related symptoms.

Of the people with STI-related symptoms in the past 12 months, 34\% reported that an STI was indeed diagnosed; 50\% reported that no STI was diagnosed and 16\% did not know the result of testing or had not visited a health-care-provider for their STI-related symptoms. In total, 19 persons (16\%) reported both STI-related symptoms in the last year and also an earlier STI before.

Multivariate logistic regression analysis showed that young age (odds ratio [OR] 12.3), Surinamese or Antillean ethnicity (OR 4.7) and homosexual orientation (OR 3.7) were independent risk factors for STIrelated symptoms in the last year (Table 2).

\section{[TABLE 1][TABLE 2]}

\section{History of STI}

If we look at the history of STI, 242 persons reported one or more STI-episodes before the last year. Together with the verified STI diagnoses among the people with STI-related symptoms in the previous 12 months, 262 of the population $>18$ years (2.7\%) reported a history of STI. In the age category 18-44, this was 3.7\%. A significantly higher history of STI is reported by single people (5.2\%), Surinamese/ Antillean persons (8.6\%), persons with a homosexual orientation (5.1\%) and persons living in deprived areas (9\%) (see Table 1). In a multivariate analysis, the probability of reporting a history of STI increased with age until 35-44 year (OR 6.0) and decreased thereafter. Also being divorced (OR 3.5), being single (OR 2.6) and living in urban (OR 2.0) or rural areas (OR 0.4) showed an independent statistically significant association (see Table 2).

\section{Health-care seeking behaviour}

Of all persons reporting in the last year, signs and symptoms which they thought were suggestive of an STI: 63\% (73/116) had visited the GP and 20\% (24/116) visited an STI- or MHS-clinic; 9\% (10/116) reported not having taken any action; eight reported visiting a different provider (e.g. gynaecologist, sexual health clinic). For one person, information on his health-seeking behaviour was missing. Table 3 depicts health-care-seeking behaviour according to different characteristics. Older persons, people living in rural area, married people and those with a homosexual orientation visited the GP less frequently.

Non-Dutch participants opted slightly more often for the GP compared with Dutch participants. In multivariate analysis, no significant associations were found as ORs had very large confidence intervals due to limited numbers in most cells. 
Bergen, J.E.A.M. van, Kerssens, J.J., Schellevis, F.G., Sandfort, T.G., Coenen, T.T., Bindels, P.J. Sexually transmitted infection health-care seeking behaviour in the Netherlands: general practitioner attends to the majority of sexually transmitted infection consultations. International Journal of STD \& AIDS: 2007, 18(6), 374379

\section{DISCUSSION}

This general practice-based nationwide study provides representative population-based (not STI-clinicbased) information about STI and STI-related health-care-seeking behaviour in the Netherlands. Among persons aged 18 years and older, 1.2\% reported STI-related symptoms in the previous year and $2.7 \%$ had a history of STI. The study shows that in the Netherlands 62\% of persons with STI-related symptoms visited the GP. Only 20\% went to an STD- or MHS- clinic. Availability of these clinics in the Netherlands is limited to the larger cities ${ }^{2}$, which makes the GP an important player in STI care.

Of the interviewees aged 18-24 years, 5\% reported STI-like complaints in the previous 12 months, and a history of STI was reported by almost $4 \%$ of the 18-44 year olds. The last sexual health survey in the Netherlands among 18- to 50-year-old persons was more than 10 years previously, and will be updated soon. In that survey, less than 1\% reported STI in 2005 and $7 \%$ a (lifetime) history of STI. ${ }^{8}$ In the UK National Survey on Sexual Health and Lifestyles (NATSAL), 10.8\% of sexually experienced men and $12.6 \%$ of sexually experienced women reported ever having an STI. ${ }^{9}$ This difference, being more than double, is striking because both study methods consisted of a computer-assisted interview at home for more than one hour, and both were large population probability samples of approximately 10,000 persons. The focus of the NATSAL study was entirely on sexual health; the 2NSGP had a broader health perspective, which could affect people's preparedness to answer STI-related questions.

However, different sexual health indicators, such as teenage pregnancy and abortion rates, are also substantially lower in the Netherlands compared with the UK.

Remarkably, people living in rural areas visited the GP for STI-related complaints less frequently, although access to other care-providers in rural areas is more difficult.

Anonymity of other services, especially for people living in rural areas, for older people and for married people might still be a reason for this health-care-seeking behaviour. The numbers are, however, too small to make any firm conclusions.

The argument of anonymity might also account for persons with a homosexual orientation who appeared to visit the GP less for STI-related symptoms. Also, the perceived higher quality of care in STI clinics has been raised repeatedly by persons with a homosexual lifestyle as an argument for their seeking this type of care. ${ }^{10}$ However, other studies among homosexual men in the Netherlands showed that still more than half would visit the GP in case of STI suspicion ${ }^{11}$ or for a HIV test. ${ }^{12}$ Our risk factor analysis does not seem to point in the direction that different risk-categories exist in primary care compared with those identified in STI- and MHS- clinics.

These clinics also report higher prevalences among MSM and ethnic minorities (especially Surinamese/Antillean).

This would mean that sentinel surveillance data from STI clinics will pick up emerging and re-emerging STI in these groups, and do this more proficiently because of the concentration of risk-categories, standardization of care and a registration and early warning system in place.

This study showed that $9 \%$ of the interviewees reported not having taken any action and did not visit any professional, although they thought they had signs or symptoms suggestive of an STI. Delay behaviour was reported already in a previous survey in the Netherlands: $27 \%$ of the study population $(n=585)$ of individuals with STI-related symptoms waited more than four weeks before they sought medical treatment. ${ }^{13}$ More attention to (early) health-care-seeking behaviour, in case of STI suspicion, is warranted in prevention campaigns.

A limitation of the study is the fact that we only addressed STI-related complaints as perceived by the patients themselves and (whether or not) confirmed by a medical professional. Many STIs are asymptomatical or subclinical and not recognized either by the patient or by the doctor. Thus, the data do not give us an insight into the (true) population burden of STI for which population-based prevalence studies would be required.

However, in this study, we were predominantly interested in STI health-care-seeking behaviour which is driven by subjective perceptions of patients about the origin of the disease.

Also, the indicator 'history of STI' can be prone to biases, not only due to reporting errors and sampling techniques, but also due to different testing behaviours for STI within and between countries. With accelerated testing, more people will be aware that they have been (asymptomatically) infected. 
Bergen, J.E.A.M. van, Kerssens, J.J., Schellevis, F.G., Sandfort, T.G., Coenen, T.T., Bindels, P.J. Sexually transmitted infection health-care seeking behaviour in the Netherlands: general practitioner attends to the majority of sexually transmitted infection consultations. International Journal of STD \& AIDS: 2007, 18(6), 374379

Another limitation of the study is the fact that health-care-seeking behaviour was only studied for persons 18 years and older. People are increasingly sexually active at a young age, and, for youngsters, additional barriers might exist that influence their health-care-seeking behaviour.

In conclusion, the GP is an important player in STI care in the Netherlands, and most consultations for STI-related symptoms are in primary care. We found considerable heterogeneity among persons who reported STI-related symptoms and a history of STI. The role of the GP in sexual health is broader than merely diagnosis and treatment of STI. Tailored prevention, active case detection and screening among risk groups are equally important. We recommend more in-depth research about the performance of GPs in STIrelated problems.

\section{[TABLE 3]}

\section{ACKNOWLEDGEMENTS}

We thank Kees Bolt for critical analysis of the preliminary data, GlaxoSmithKline for additional financial support for this study, and the Funding body: Ministry of Health Netherlands. Ethical approval: The study was conducted according to the Dutch legislation on data protection.

\section{REFERENCES}

1 Fennema H. Annual Report STD Clinic Amsterdam 2002 [Dutch].

Amsterdam, 2003

2 Coenen AJ, Berends R, Van der Meijden WI. The organization of STI control in the Netherlands - an overview. Int J STD AIDS 2002;13: 254-260

3 Vlasblom R, van Bergen J, van Veen M, van de Laar M. Increase in STI continues (Dutch). STI Bull 2003;24:4-5

4 Nicoll A, Hamers FF. Are trends in HIV, gonorrhea and syphilis worsening in Western Europe. BMJ 2002;324:1324-7

5 Simms I, Hurtig AK, Rogers PA, et al. Surveillance of sexually transmitted infections in primary care. Sex Transm Infect 2003;79: 174-176

6 Howards PP. Do clinic-based STD data reflect community patterns? Int J STD AIDS 2002;13:11

7 Westert GP, Schellevis FG, de Bakker DH, Groenewegen PP, Bensing JM, van der Zee J. Monitoring health inequalities through General Practice: the second Dutch National Survey of General Practice. Eur J Public Health 2005;15:59-65

8 van Zessen G, Sandfort Th. Sexuality in the Netherlands: Sexual Behavior, Risk and Prevention of AIDS [Dutch]. Amsterdam: Swets and Zeitlinger, 1991

9 Fenton KA, Korovessis C, Johnson AM, et al. Sexual behaviour in Britain: reported sexually transmitted infections and prevalent genital Chlamydia trachomatis infection. Lancet 2001;358:1851-4

10 Leenaars PEM, Rombouts R, Kok G. Service attributes and the choice for STD health services in persons seeking a medical examination for an STD. Soc Sci Med 1994;38:363-71

11 Sandfort Th G M, de Vroome E. Homosexual men and 'ordinary' STI. Homostudies/ISOR. Utrecht: University of Utrecht, 1996

12 Hospers HJ, Do" rfler TT, Zuilhof W. Monitor onderzoek 2003 [Dutch] 90-7334-120-5 ISBN. Amsterdam: Schorer, 2003

13 Leenaarts PEM, Rombouts R, Kok G. Seeking medical care for a sexually transmitted disease: determinants of delay-behavior. Psychol Health 1993;8:17-32 
Bergen, J.E.A.M. van, Kerssens, J.J., Schellevis, F.G., Sandfort, T.G., Coenen, T.T., Bindels, P.J. Sexually transmitted infection health-care seeking behaviour in the Netherlands: general practitioner attends to the majority of sexually transmitted infection consultations. International Journal of STD \& AIDS: 2007, 18(6), 374-

\section{TABLES}

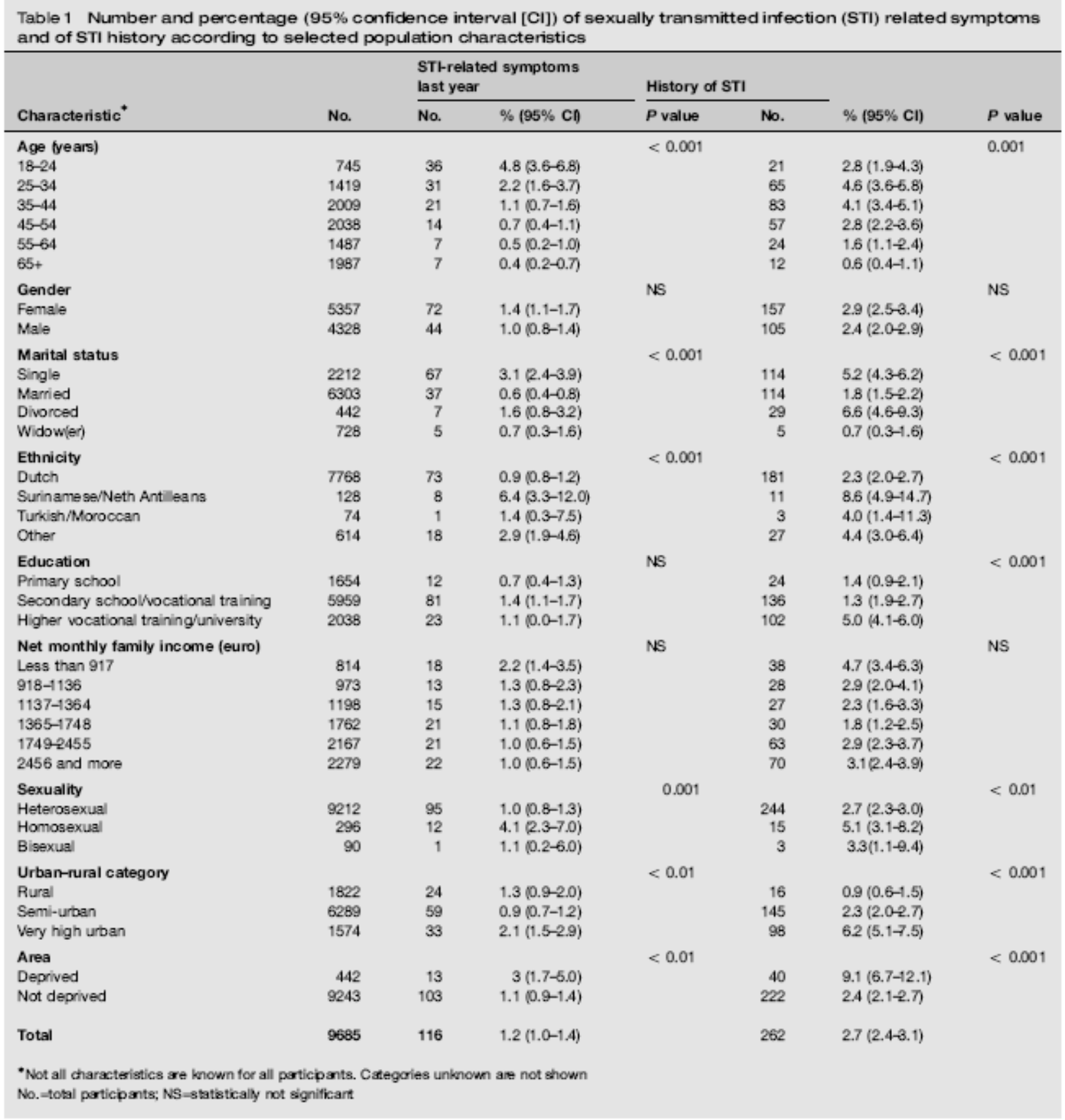


Bergen, J.E.A.M. van, Kerssens, J.J., Schellevis, F.G., Sandfort, T.G., Coenen, T.T., Bindels, P.J. Sexually transmitted infection health-care seeking behaviour in the Netherlands: general practitioner attends to the majority of sexually transmitted infection consultations. International Journal of STD \& AIDS: 2007, 18(6), 374-

\begin{tabular}{|c|c|c|}
\hline Characteristic & $\begin{array}{l}\text { STl-related } \\
\text { symptoms last year } \\
\text { Odds ratio }(25.0 \% \mathrm{Cl})\end{array}$ & $\begin{array}{l}\text { History of STI } \\
\text { Odds ratio }(95.0 \% \\
\text { CI) }\end{array}$ \\
\hline \multicolumn{3}{|l|}{ Age (years) } \\
\hline $65+$ & 1.0 & 1.0 \\
\hline $55-64$ & $1.6(0.5-4.9)$ & $2.7(1.3-5.5)$ \\
\hline $45-64$ & $2.2(0.7-6.1)$ & $4.3(2.2-8.3)$ \\
\hline $35-44$ & $3.5(1.3-9.4)$ & $6.0(3.1-11.5)$ \\
\hline $25-34$ & $6.9(2.6-18.6)$ & $5.5(2.8-10.9)$ \\
\hline $18-24$ & $12.3(4.3-34.8)$ & $2.6(1.2-5.6)$ \\
\hline \multicolumn{3}{|l|}{ Marital status } \\
\hline Widow(er) & 1.0 & 1.0 \\
\hline Single & $0.8(0.3-2.5)$ & $2.5(1.0-6.8)$ \\
\hline Divorced & $1.0(0.3-3.7)$ & $3.5(1.3-9.6)$ \\
\hline Married & $0.4(0.1-1.2)$ & $1.1(0.4-3.0)$ \\
\hline \multicolumn{3}{|l|}{ Ethnicity } \\
\hline Dutch & 1.0 & 1.0 \\
\hline Other ethnicity & $2.7(1.6-4.7)$ & $1.4(0.9-2.1)$ \\
\hline $\begin{array}{l}\text { Surinamese/Nkth } \\
\text { Ant leans }\end{array}$ & $4.7(2.0-10.8)$ & $1.3(0.6-2.6)$ \\
\hline Turkish/Moroccan & $0.7(0.1-5.5)$ & $0.8(0.3-2.8)$ \\
\hline \multicolumn{3}{|l|}{ Sexuality } \\
\hline Heterosexual & 1.0 & 1.0 \\
\hline Homosexual & $3.7(2.0-7.1)$ & $1.6(0.9-2.8)$ \\
\hline Bisexual & $1.0(0.1-7.5)$ & $0.9(0.3-3.1)$ \\
\hline \multicolumn{3}{|l|}{ Urban-rural } \\
\hline Semi-urban & 1.0 & 1.0 \\
\hline Rural & $1.7(1.0-2.7)$ & $0.4(0.3-0.7)$ \\
\hline Very high urban & $1.6(1.0-2.7)$ & $2.0(1.5-2.8)$ \\
\hline \multicolumn{3}{|l|}{ Area } \\
\hline Not deprived & 1.0 & 1.0 \\
\hline \multirow[t]{3}{*}{ Deprived area } & $1.1(0.5-2.3)$ & $1.5(1.0-2.3)$ \\
\hline & Hosmer and & Hosmer and \\
\hline & Lemeshow test: 5,9 & Lemeshow test: 3,2 \\
\hline
\end{tabular}


